\title{
HYDROLOGIC STUDY OF JEWEL AND WIND CAVES
}

E. Calvin Alexander, Jr.

Department of Geology and Geophysics

University of Minnesota

Minneapolis

\section{Objectives}

The research underway has the following objectives:

1. To evaluate the water distribution within these two park areas;

2. To determine the effects of human impact upon the natural hydrologic systern;

3. To document any detrimental effects to the water quality;

4. To document any instances in which the cave environment is adversely affected by the quality or quantity of the water present; and

5. To provide options to present water use practives, if necessary.

\section{Methods}

The objectives of the research are being accomplished in three, overlapping phases which were outlined in the proposal. Phase I involves compilation of the available information on the caves' location, geology and hydrology and correlation of that information with the surface topography and the location of all surface hydrologic and artificial features. The goal of phase $I$ is to compile available information that is currently scattered in various files and individual records and memories.

Phase II is as complete as possible a chemical characterization of the surface and subsurface waters in the two areas. This phase involves chemical analyses of major cation and anion species, selected trace elements, synthetic organic compounds and/or natural and anthropogenic isotopic species in the waters.

Phase III is an investigation of infiltration of surface waters into the caves. Correlation of the chemistries on surface and subsurface waters are yielding some information in this phase but the major tool is dye trace studies.

\section{Progress in 1st and 2nd Quarters of the 2nd Year}

The second summer of the project has yielded many accomplishments in the 
field. Water samples continued to be collected from a variety of locations: 1) four drip sites and one pool in Wind Cave, along, or near, the scenic route, 2) five drip sites along the scenic tour route and three pools in Jewel Cave, 3) five springs and one well in Hell Canyon south of the Jewel Cave boundary, 4) eight springs and one well in and around the town of Hot Springs, 5) one of the springs at Buffalo Gap, and 6) the water wells at Wind and Jewel Caves. The temperature and $\mathrm{pH}$ of these waters were determined during sampling, and the alkalinity within a few hours of collection. Cations and anions were analyzed on samples returned to the University of Minnesota.

One of the sample sites, Methodist Church, along the scenic route in Wind Cave has shown a high and variable nitrate-nitrogen content. The data from Methodist Church drips are shown in Figure 1. The nitrate values measured in August and November 1985, 3.1 and $3.6 \mathrm{ppm}$, were the highest observed in the Wind Cave area but were well below the $10 \mathrm{ppm}$ drinking water limit for nitrates.

When resa mpled in May and July of 1986, the nitrate values were 10.4 and 10.5 ppm - - i.e. above the drinking water standard. The values measured in August, September and October, 1986 are back down in the 2 to 3 ppm range. Apparently, during the spring and early summer the values are much higher than in the fall. The localized presence of nitrates in varying a mounts suggests pulse input in which rainfall events flush nitrates downward into the cave. The interesting problem is determining the source of the nitrate in this nonagricultural area. It is possible that the land surface over this part of the cave was used for some other purpose than its current use during the early development of Wind Cave. Our current working hypothesis is that a late 1800 s privy or stable may have existed in this area and the nitrates are being leached downward from such abandoned (and forgotten) installations. Hopefully an answer can be found in the Park's archives.

The water supply wells for the two parks were tested for tritium content along with resampling for ${ }^{14} \mathrm{C}$ to obtain a better grasp on the residence time of water recharged to the aquifer in these areas. The tritium values show the Jewel Cave well water to be older than the well water at Wind Cave.

We have been analyzing water samples from several springs and a few wells in the down gradient direction of both caves, searching for possible resurgences of water that has recharged the aquifer in the vicinity of the two caves. Variations in temperature and concentration of chemical constituents between springs in close proximity to one another, suggest a more complicated hydrologic system than originally thought. While Calvin Alexander was attending another meeting this September he had an opportunity to discuss with USGS personnel from Denver the testing of groundwater to determine the influence of radiogenic heat production on temperature anomalies we have been finding. Samples from these springs are being analyzed for trace cations and uranium, radon and helium to evaluate the cause of hydrothermal activity and to help delineate the chemical evolution of recharge waters from the surface, through the caves to these hypothesized resurgences.

Six dripping areas along the scenic route in Wind Cave have been analyzed for 


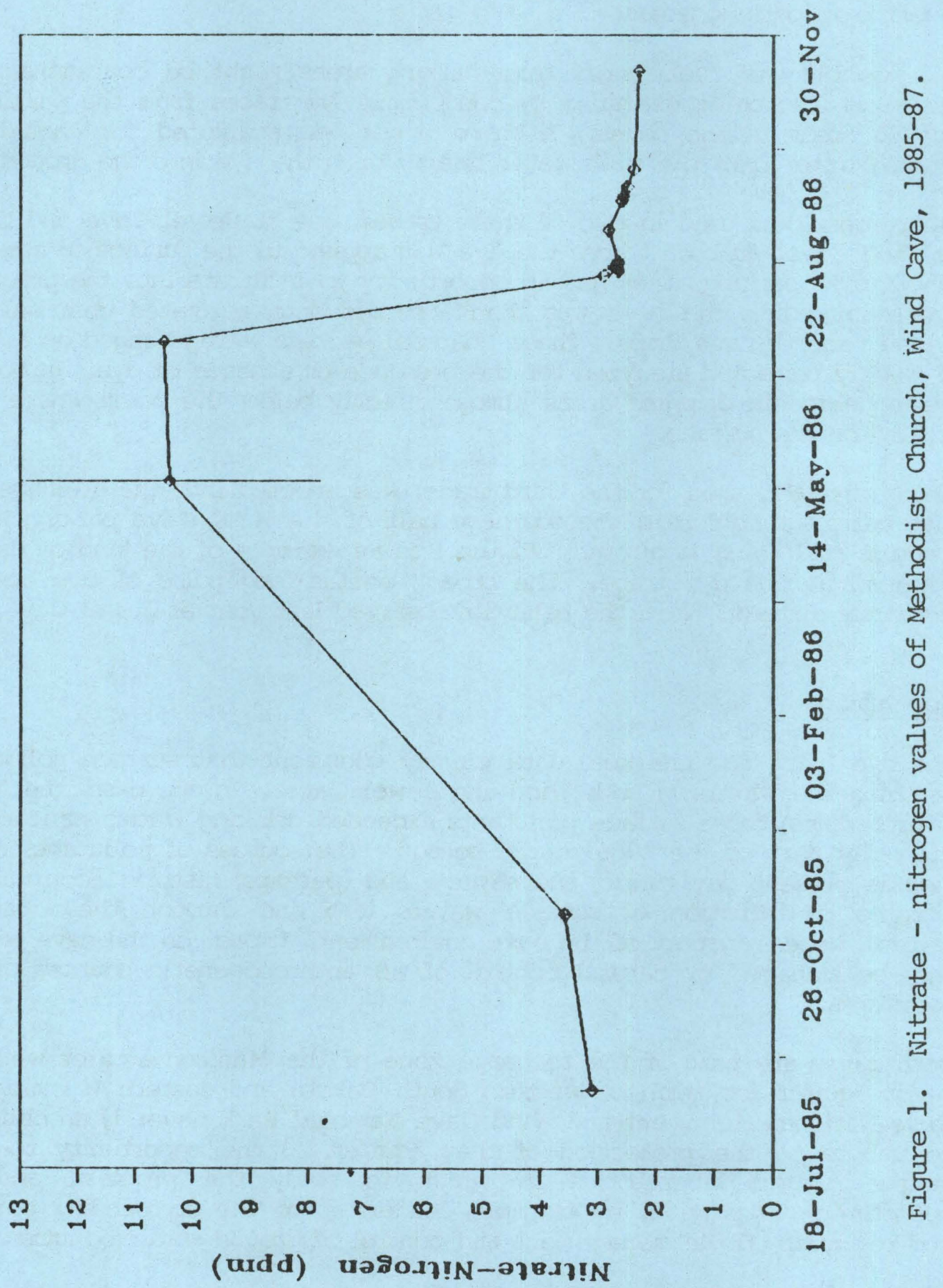


aromatic hydrocarbons. These drip sites include ones shown to be along the flow paths identified for surface runoff from the parking lot by the dye traces. Only one of the samples contained any evidence of volatile hydrocarbons and that datum was barely above the detection limit. These analyses were designed to search for hydrocarbon contamination from leaking buried fuel tanks and/or fuel runoff from parking areas.

The possiblity of fuel runoff from parking areas might be contaminating cave waters is also being examined by conducting dye traces from the parking areas to wet areas in the caves. A storm event was simulated for each trace by running water from the main water line to flush the dye into the ground.

Fluorescene was used in two of these traces, one at Jewel Cave and the other at Wind Cave. In both traces the dye was applied to the surface in areas where runoff from parking areas has an opportunity to infiltrate into the ground. Any dye seeping into the cave was then absorbed onto activated charcoal packets placed beneath cave drips. These charcoal packets were changed on a biweekly to weekly basis and analyzed for the presence or absence of dye. In both caves dye appeared in dripping areas almost directly below the point where dye was applied on the surface.

Rhodamine WT, used for the third trace, was injected into the drainage channel that carries runoff from the southern half of the Wind Cave parking lot. This trace is still being monitored. Figure 2 is an example of the kind of data being obtained in this dye trace. The broad, months long pulse of dye observed is distinctly different from the behavior observed last year at Jewel Cave.

\section{Conclusions}

The dye trace and chemical data clearly document that surface pollutants are reaching the waters in both Wind and Jewel Caves. In one case, the Methodist Church drips, those surface pollutants exceeded drinking water standards during the early part of the 1986 tourist season. The sources of pollutants appear to include present day runoff and sewage and (perhaps) historic accumulations of nitrates. Infiltration of surface waters into and through these caves is a natural, necessary part of the cave environment. Impact on the cave waters can only be managed by careful control of all anthropogenetic sources of surface pollutants.

Both caves are part of the recharge zone of the Madison aquifer which is the major aquifer for much of western South Dakota and eastern Wyoming. Jewel Cave National Monument and Wind Cave National Park have: 1) an obligation to contribute to the protection of that aquifer, 2) the opportunity to serve as unique natural laboratories in which to study the problem, and 3) the opportunity to provide, by example, leadership to the surrounding com munities and residents on the manage ment and control of ground water pollution. 


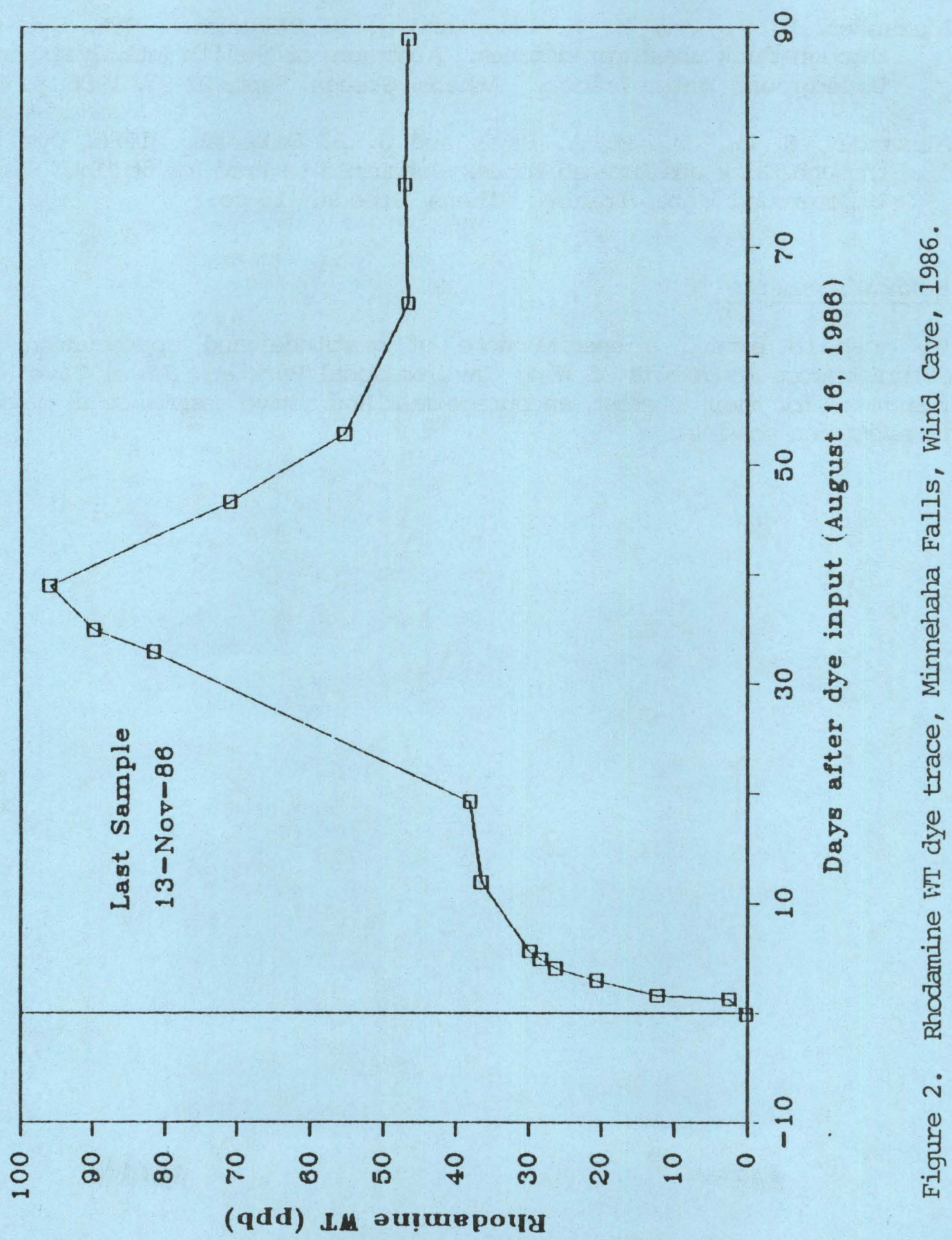




\section{Publications Based on this Project}

Davis, M. A. and E. C. Alexander, Jr. 1986. Impact of surface development on water quality in Wind and Jewel Caves. Conf. on Sci. in the Natl. Parks, Prog. and Abstracts, Ft. Collins, CO, July 13-18, 1986. p. 242.

Alexander, E. C., Jr., M. A. Davis and J. B. Dalgleish. 1986. Dye tracing through thick unsaturated zones. Abstracts of the 5th Intl. Symp. on Underground Water Tracing. Athens, Greece, Sept. 22-27, 1986. p. 43-44.

Alexander, E. C., Jr., M. A. Davis and J. B. Dalgleish. 1986. Dye tracing through thick unsaturated zones. Submitted to Proc. of 5th Intl. Symp. on Underground Water Tracing, Athens, Greece. 15 pp.

\section{Acknowlegements}

We wish to extend a special note of gratitude and appreciation to the administrators and staffs of Wind Cave National Park and Jewel Cave National Monument for their interest, encouragement and active assistance in making this investigation possible. 